Article

\title{
The Structural Efficiency of Tapered Steel Section with Perforation under Lateral Torsional Buckling Behaviour
}

\author{
Fatimah De'nan ${ }^{1 *}$, Nor Salwani Hashim² and Lim Cheng Kuan ${ }^{3,}$ \\ ${ }^{1,2,3}$ School of Civil Engineering, Engineering Campus, Universiti Sains Malaysia, 14300 Nibong Tebal, \\ Pulau Pinang, Malaysia \\ 2; wani_a02@yahoo.com; 3; cklim9496@gmail.com \\ * Correspondence: cefatimah@usm.com; Tel.: +6013-4800037
}

\begin{abstract}
Purpose - Tapered section can resist maximum stress at a single location while the stresses are considerably lower at the rest of the member and therefore it could have higher structural efficiency compared to conventional section. It could also satisfy functional requirements while reducing weight and cost in many fields of civil construction. Perforation in the steel section also eases the integration of Mechanical and Electrical (M\&E) services such as ventilation pipes and electrical cables within the structural depths of the beam. In this analysis, the structural efficiency of tapered steel section with perforation under lateral-torsional buckling behaviour is investigated.
\end{abstract}

Design/methodology/approach - A total of eighty one models are analysed using LUSAS software and five variables are investigated which involved perforation sizes, perforation shapes, perforation layout, tapering ratio and flange and web thickness. Buckling moment is obtained from the analysis results in LUSAS software while self-weight and structural efficiency are manually calculated.

Findings - Perforation size of $0.75 \mathrm{D}$ has the highest structural efficiency although it can withstand a smaller buckling load. This is due to its lower self-weight compared to other perforation sizes. The square perforation shape also has the highest structural efficiency compared to circular perforation and diamond perforation. An increment of percentage in structural efficiency of the square perforation shape with $0.75 \mathrm{D}$ is the highest at $3.07 \%$. The circular perforation shape with $0.75 D$ (Open-Open-Open perforation layout) has the highest increment of percentage in structural efficiency which is $2.37 \%$. The tapering ratio of 0.3 is the most efficient and an increment of percentage in structural efficiency is $114.36 \%$. The flange thickness of $0.02 \mathrm{~m}$ and web thickness of $0.015 \mathrm{~m}$ has the highest structural efficiency at 45.756 and 29.171 respectively.

Originality/value - In conclusion, a section should be able to resist the large buckling moment and has a lower self-weight in order to achieve high structural efficiency.

Keywords: tapered steel section, perforation, lateral torsional buckling behavior, LUSAS 14.0, structural efficiency

\section{Introduction}

Structural steel section widely used by engineers especially in those developed countries due to its ease of erection. Steel section provides a better mechanical section property and at the same time fulfills the architectural needs (Sehwail, 2013). The cost has always been an important factor to reduce the construction costs. It could result in reducing the labour cost as steel section can be constructed in a smooth process. Besides that, steel industry significantly reduced the emissions of greenhouse gases due to its high recycled content and recycling rate compare to other construction material (AISC, 2018). 
The conventional I-beams frequently used to sustain bending moments due to the higher ratio of moment inertia to area. (Thomas, 2014). Tapered beams can resist maximum stress in certain location meanwhile the stresses were considerably lower in the rest of the section. This contributes to materials saving and lower construction cost (Polyzois and Raftoyiannis, 1998). As found by Wijaya et. al, 2019, the elastic buckling governs the critical moment and the stresses at peak load was in elastic range. For beams with $8 \mathrm{~m}$ span, the collapse analysis result show the stresses at the peak load in the flange section were in inelastic range. Therefore, the long beam was close to the collapse behaviour which makes those beams not in safe design. Moreover, the web-post width was the most important parameter that affects the failure mode (Durif et. al, 2012). The taper ratio significantly control the buckling stress, as the taper ratio increases, the buckling stress ratio decreases while slenderness ratio has minor influence in predicting the buckling stress (Rameshbabu and Prabavathy, 2018).

Lateral torsional buckling was one of the common failure modes in tapered steel section with perforation. Sehwail, 2013 states that the beam with the thicker flange acted more efficient in bending strength. This was due to the twisting behaviour was resisted by the torsional stiffness which mainly governed by the section flange thickness. Azar et. al, 2016 states that thickness of the web, the thickness of the flange, opening size, tapering ratio and opening arrangement influences the buckling moment of tapered steel section with perforation. The recommended section for tapered steel section with perforation under the lateral-torsional buckling was the opening size ranges from $0.2 \mathrm{D}$ to $0.4 \mathrm{D}$, with a tapering ratio of 0.3 and Open-Close-Open arrangement. However, from research done by Azar et. al, 2016 the effect of self-weight was not considered.

Perforation geometry significantly influences load-carrying capacity in term of ultimate load for the section with web perforation (Rodrigues et. al, 2014; Tankova et. al, 2018 and Bai et. al, 2019). Asgarian et. al, 2013 states that the lateral buckling moments gradually decreases as the tapering ratio decreases. Besides that, lateral buckling moment's increases with the reduction in span length.

For the stepped beam subjected to uniform bending, additional plates attached to the flanges in the middle half of a section which contributed to the increment of two times in second moment of area compared to that of the original beam Iy2 $=2 \mathrm{Iy} 1$, and 1.44 times plastic section modulus compared to that of original beam (Kucukler et. al, 2015). However, the presence of perforation can be neglected to calculate the lateral torsional buckling strength for honeycomb beam by limiting the unbraced length for yielding limit state and the factor of reduction was near to 1.0 (Gunawan and Suryoatmono, 2017). In the assessment for the lateral-torsional buckling moment of elliptical cellular beams due to consideration of section properties at the web-post section, the AISC standard equation was considered. The unconservative design results from the finite element analysis (FEA) shown that about 5 percent in elastic range and more than 20 percent in inelastic and plastic range was observed (Phuvorayan and Ponsorn, 2017).

Due to the existence of stiffener fillet and stiffener length, the axial capacity of cold formed steel (CFS) channels with edge-stiffened holes were slightly enhanced, meanwhile the lower axial strengths observed due to the hole spacing and hole diameter (Chen et. al, 2020). Besides that, the compression resistance increased by $21 \%$, compared to that of the plain channel section by using channel section with seven edge-stiffened web openings. However, $20 \%$ reduction in compression resistance for unstiffened section compared to that of plain channel section (Chen et. al, 2019).

Steel structures were considered higher load-carrying capacity with a low self-weight. The self-weight of steel section mainly depend on the shapes and the size of perforation (Hasan et. al, 2014). Structural efficiency was measured in terms of material weight which should be provided to carry a given amount of load (Hasan et. al, 2014). It was possible to precisely determine the level of structural efficiency based on two main parameters which were the load-carrying capacity and self-weight of the section.

\section{Methodology}

LUSAS 14.0 software was used in this analysis to investigate the efficiency of tapered steel section with perforation to lateral-torsional buckling behaviour. In this analysis, thin shell element quadrilateral (QSL8) was assigned to the finite element model of the tapered steel section with perforation. The material used was ungraded mild steel with default value; Young's Modulus, $E$ was $209 \times 10^{3} \mathrm{~N} / \mathrm{mm}^{2}, 0.008 \times 10^{-6} \mathrm{~N} / \mathrm{mm}^{2}$ for the density, 0.3 of Poisson ratio and $0.011 \times 10^{-3}$ for the coefficient of thermal expansion. Fixed support was assigned to the $h_{\max }$ (maximum depth of the beam at the other end) and fixed translation and rotation. Free translation and rotation at $h_{\min }$ (minimum depth of the beam at one end) as it acted a cantilever beam. $10 \mathrm{kN}$ 
concentrated load was applied at the free end of the section at the top part of the flange in vertical y-axis direction.

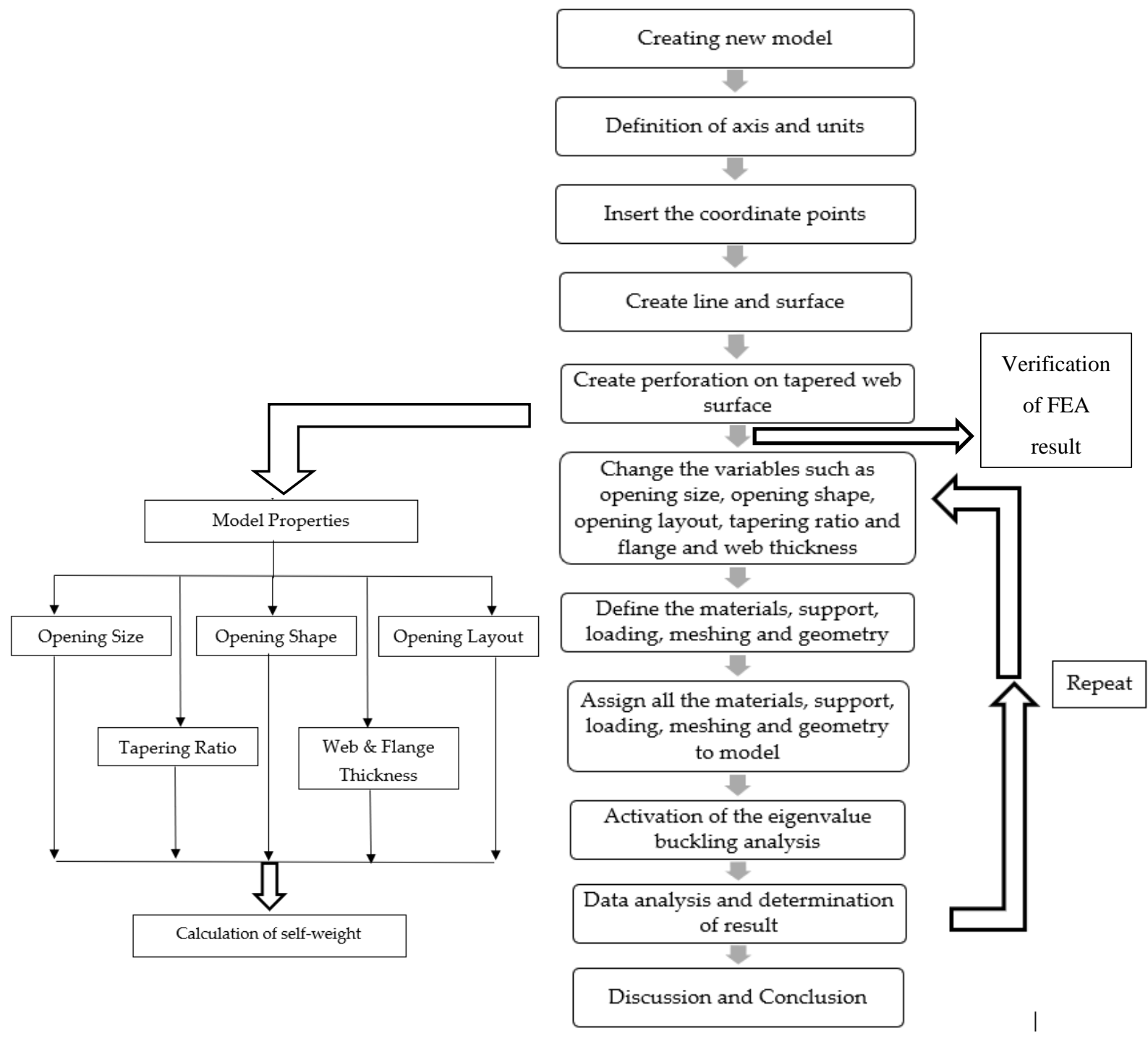

Figure 1. Modelling flow chart using LUSAS software

A convergence study was carried out to obtain an optimum mesh size to reduce the computational effort. In the convergence study, the element size gradually decreases caused the mesh density an increment of mesh density. The dimensional properties of the model used in convergence study are shown in Table 1 which $D$ is height of section and $W$ is width of section.

Table 1. Dimensional Properties of Sample Models

\begin{tabular}{cc}
\hline Section & I-beam \\
\hline Section depth, $D(\mathrm{~mm})$ & 500 \\
Section width, $W(\mathrm{~mm})$ & 200 \\
Web thickness, $t_{\mathrm{w}}(\mathrm{mm})$ & 9 \\
Flange thickness, $t_{\mathrm{f}}(\mathrm{mm})$ & 13 \\
Span, $L(\mathrm{~mm})$ & 5500 \\
Applied load, $P(\mathrm{kN})$ & 10 \\
\hline
\end{tabular}


Convergence occurs when the maximum displacement obtained as shown in Figure 2 and Table 2. From the graph of maximum displacement versus the number of elements, the graph starts to converge when the element size was 25 . Therefore, the element size of 25 is chosen throughout the analysis because any decrease in element size after element size 25 was negligible and would not have much difference.

Table 2. Data of maximum displacement of I-beam model

\begin{tabular}{cccc}
\hline Model & Size element & No of element & $\begin{array}{c}\text { Displacement } \\
\boldsymbol{\delta}(\mathbf{m m})\end{array}$ \\
\hline 1 & 70 & 869 & 6.5224 \\
2 & 60 & 1472 & 6.5234 \\
3 & 50 & 1980 & 6.5244 \\
4 & 40 & 3450 & 6.5253 \\
5 & 30 & 5307 & 6.5259 \\
6 & 25 & 7920 & 6.5262 \\
7 & 20 & 12375 & 6.5263 \\
\hline
\end{tabular}

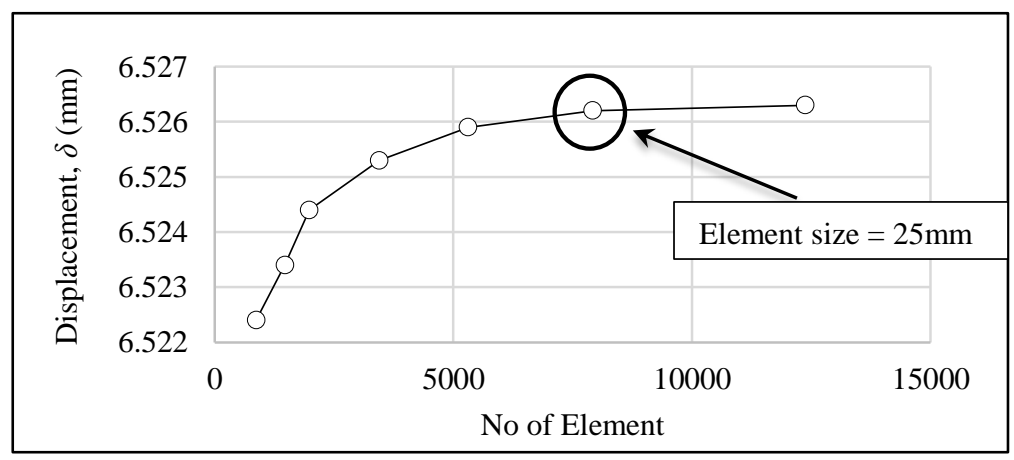

Figure 2. Graph of maximum displacement against number of elements

The formula by Azar et. al, 2016 used to calculate the buckling moment:

Buckling load $\left(P_{\mathrm{b}}\right) \quad=$ Eigenvalue $(e) \times$ Concentrated load $(P)$

Buckling moment $\left(M_{\mathrm{b}}\right)=P_{\mathrm{b}} \times$ section length $(L) / 4$

The structural efficiency as used by De'nan et. al, 2017 of all models was then calculated:

Structural efficiency $=$ Buckling moment $/$ Self-weight

The tapering ratio used is the minimum depth of the beam at one end, $h_{\min }$ to the maximum depth of the beam at the other end, $h_{\max }$. The distance from the fixed end to the first, second and third perforation is shown in Figure 3.

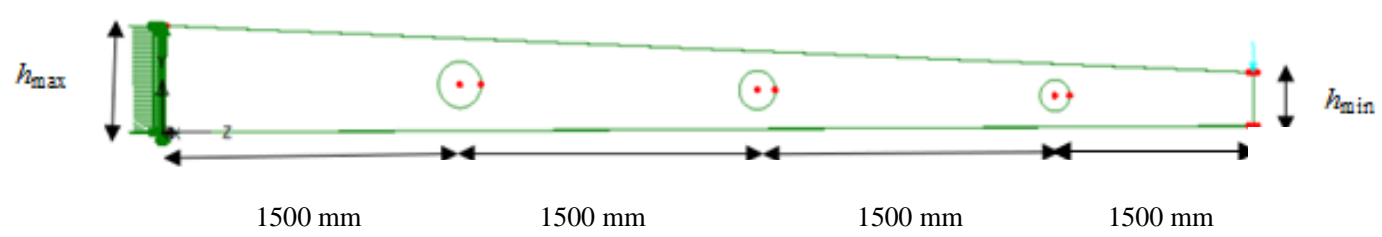

Figure 3. Visualisation of distance between perforation, maximum and minimum depth of the beam

Three perforation layouts involved which are Open-Open-Open (OOO) layout is shown in Figure 4(a), Open-Close-Open (OCO) layout is shown in Figure 4(b) and Close-Open-Close (COC) layout is shown in Figure 4(c). There are 3 perforations in the OOO layout, 2 perforations in OCO layout and 1 perforation in COC layout. 


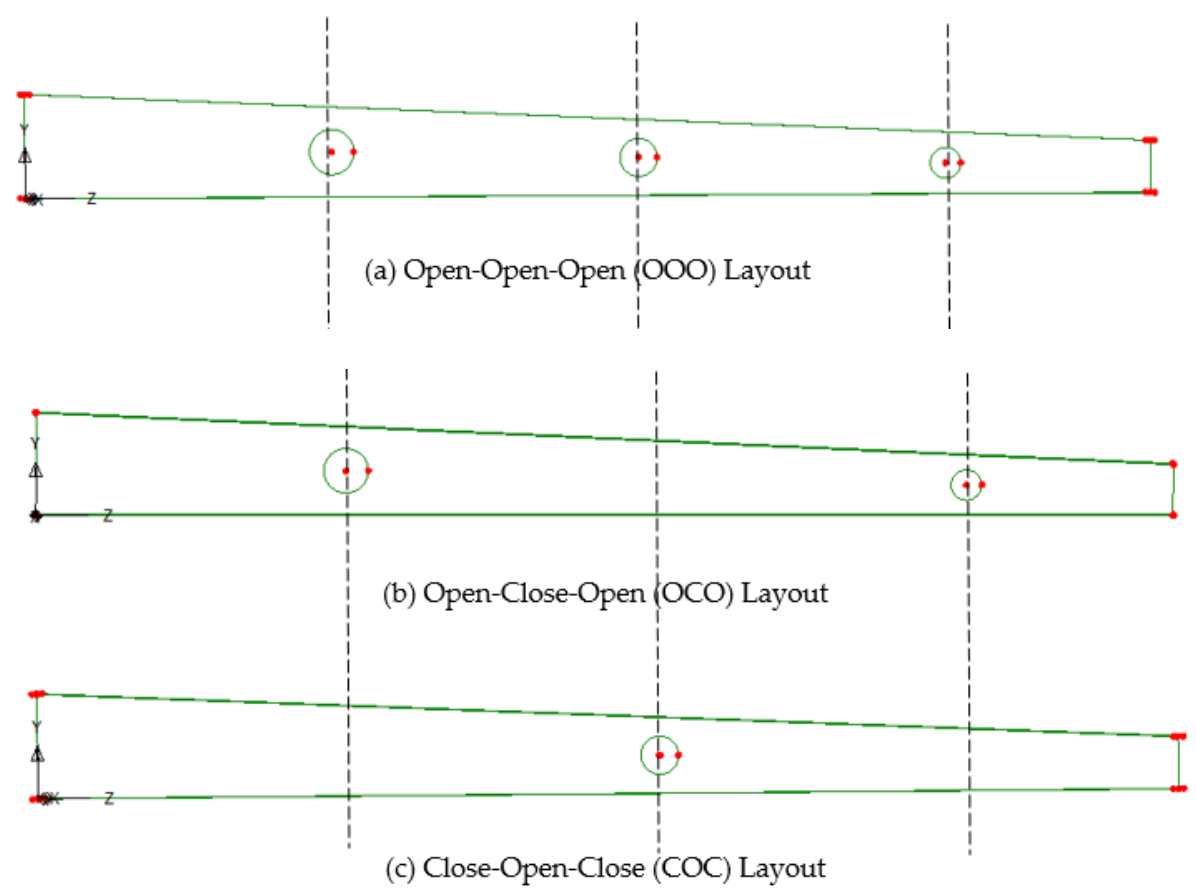

Figure 4. Perforation layout

\section{Results and Discussions}

\subsection{Result Verification of LUSAS Software}

A conventional I-beam section as shown in Figure 5 was modelled in LUSAS to obtain the maximum displacement. The displacement of the section was then compared to the theoretical calculation to verify the finite element analysis results.

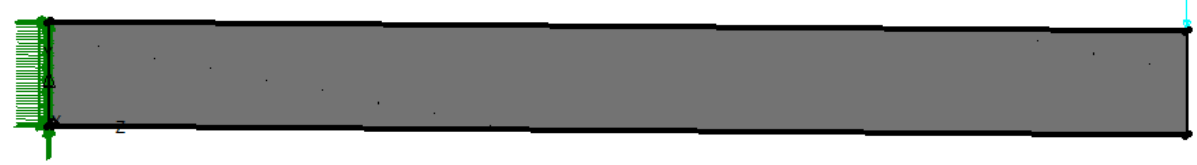

Figure 5. Uniform I-beam from LUSAS

As shown in Figure 5, the I-beam section was fixed at the left-hand side, free on the right-hand side which acted as a cantilever beam. $10 \mathrm{kN}$ was applied at the free end of the beam. Figure 6 shows the typical view of an I-beam section and Table 3 shows the section properties used. $I_{\mathrm{xx}}$ is the second moment of area about the $\mathrm{x}-\mathrm{x}$ axis, $I_{y y}$ is the second moment of area about the $\mathrm{y}$-y axis and $p$ is steel density. 


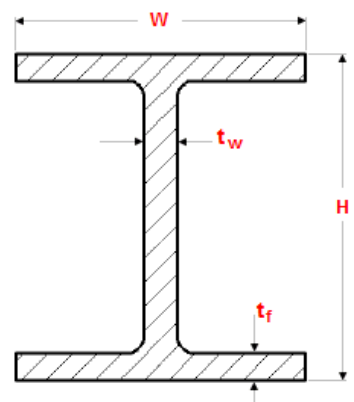

Table 3. Table of section properties

\begin{tabular}{cccc}
\hline$D$ & $500 \mathrm{~mm}$ & $I_{\mathrm{xx}}$ & $388265248 \mathrm{~mm}^{4}$ \\
$W$ & $200 \mathrm{~mm}$ & $I_{\mathrm{yy}}$ & $17362128 \mathrm{~mm}^{4}$ \\
$t_{\mathrm{f}}$ & $13 \mathrm{~mm}$ & - & - \\
$t_{\mathrm{w}}$ & $9 \mathrm{~mm}$ & - & - \\
$p$ & $7.85 \mathrm{~g} / \mathrm{cm}^{3}$ & - & - \\
\hline
\end{tabular}

Figure 6. I-section Beam

The beam deflection formula for a cantilever beam with concentrated load, $P$ loaded at the free end;

$$
\begin{aligned}
\delta_{\max } & =P L^{3} / 3 E I \\
& =\left(10 \times 10^{3} \mathrm{~N}\right)(5500 \mathrm{~mm})^{3} / 3\left(209 \times 103 \mathrm{~N} / \mathrm{mm}^{2}\right)\left(388265248 \mathrm{~mm}^{4}\right) \\
& =6.8343 \mathrm{~mm}
\end{aligned}
$$
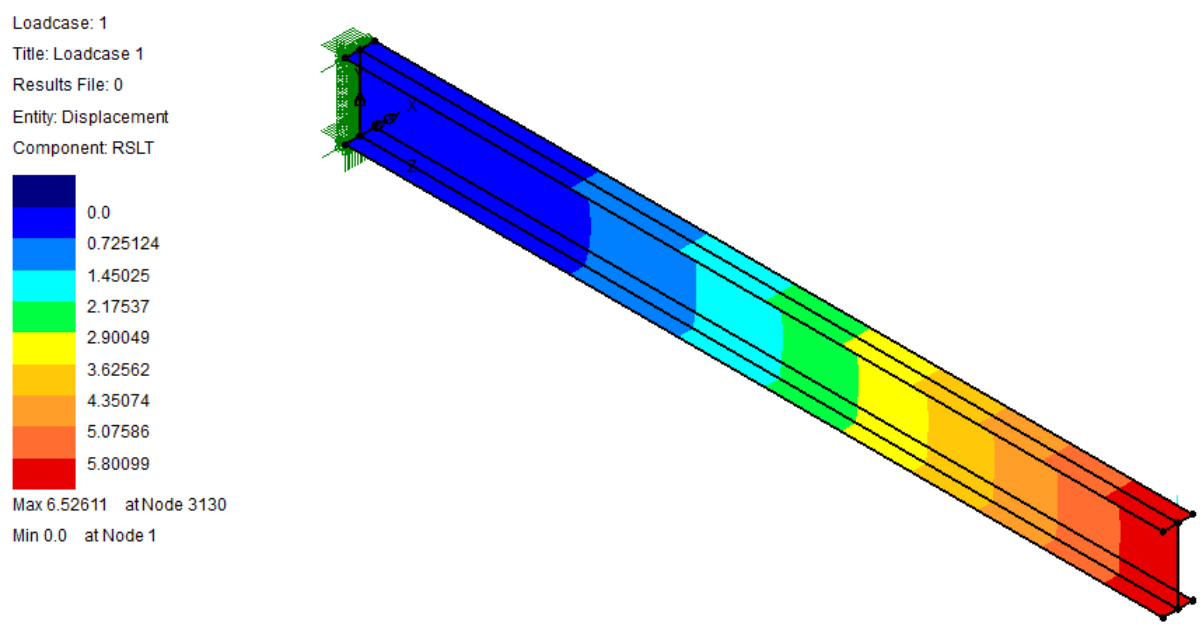

Figure 7. Displacement result from LUSAS

From Figure 7, it was observed that the deflection was higher near to the free end section as it acted similar to cantilever beam. From the LUSAS result, the maximum deflection was $6.5261 \mathrm{~mm}$. Therefore, the result difference between the LUSAS and manual calculation was calculated as $6.8343 \mathrm{~mm}-6.5261 \mathrm{~mm}=$ $0.3082 \mathrm{~mm}$. Thus, percentage difference $=[(6.8343-6.5261) / 6.8343] \times 100 \%=4.5 \%$.

The difference between the two results was only $0.3082 \mathrm{~mm}$ and the percentage difference was $4.5 \%$. The percentage difference was below $10 \%$ and therefore it was acceptable and this proves that LUSAS modeling result nearly similar to manual calculation.

\subsection{Modelling of Initial Imperfections}

Lateral torsional buckling behaviour of steel section mostly depends on the location of applied load and restraints condition. Initial imperfections (Roy et. al, 2019; Roy et. al, 2018) were considered in the FE modeling. Hence, superimposition of local and overall imperfections was considered for accurate FEA. Eigenvalue analyses of section with perforations with various web thicknesses were considered to determine the overall buckling mode. Lowest Eigenmode was from LUSAS is used as the shape of local and overall buckling mode. Eigenvalue buckling analysis predicts the theoretical buckling strength of a structure which was idealized as elastic section. In addition, local imperfections of magnitude $0.5 \%$ of the section thickness were incorporated. For a basic structural configuration, eigenvalues number were computed from the constraints and 
loading condition. For this analysis, the eigenvalue was set to 3, therefore three different modes of failure were observed. Figure 8(a), 8(b) and 8(c) shows the results for eigenvalue buckling analysis of tapered steel section with perforation.
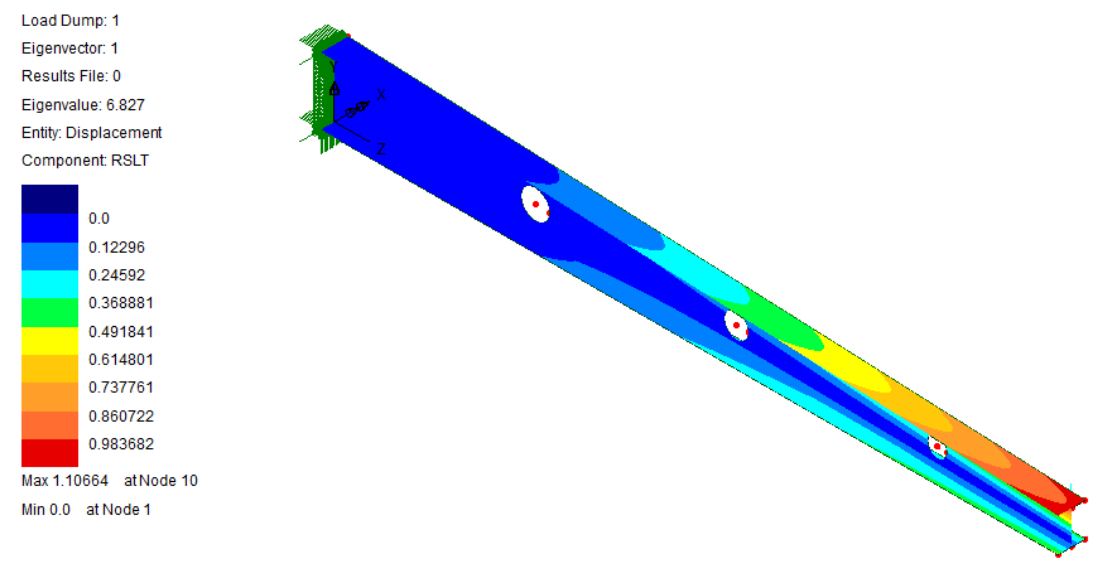

Figure 8(a). Results of eigenvalue 1
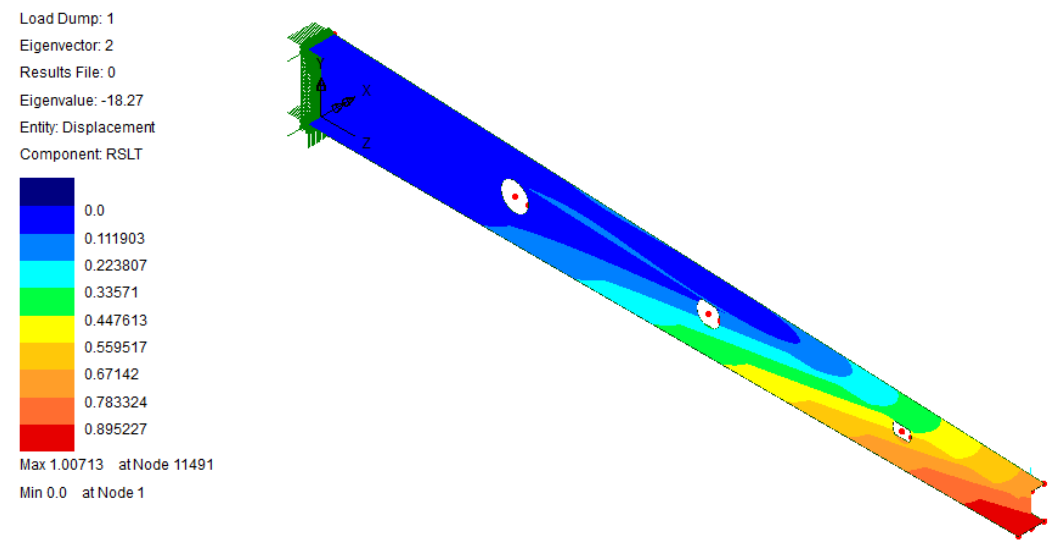

Figure 8(b). Results of eigenvalue 2
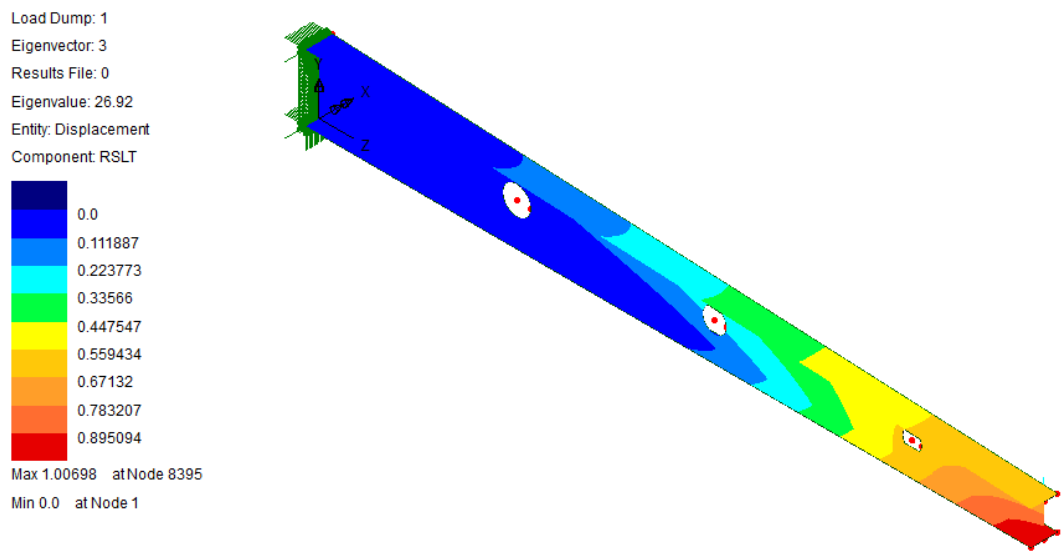

Figure 8(c). Results of eigenvalue 3

From the three eigenvalues as shown in Figure 8, the eigenvalue 1 was 6.827, eigenvalue 2 was -18.27 and eigenvalue 3 was 26.92. The first eigenvalues used to calculate the buckling moment because the first eigenvalues represent the mode of failure that was tending to occur. Therefore, the lowest buckling moment observed compared to other three eigenvalues. 
In this analysis, the structural efficiency of a beam with a particular cross-sectional shape decreases as the span length increases. Therefore, different types of efficient shapes must be used to maintain a constant level of efficiency for different span length (Macdonald, 2007). A total number of 81 models were analysed using LUSAS software. The variables involve known as the size of the perforation, the shape of the perforation, perforation layout, tapering ratio, flange thickness and web thickness.

\subsection{Effect of Perforation Size}

A total of 10 perforation size of circular perforation were analysed using LUSAS software. The perforation size were $0.3 D, 0.35 D, 0.4 D, 0.45 D, 0.5 D, 0.55 D, 0.6 D, 0.65 D, 0.7 D$ and $0.75 D$, where $D$ was the depth of section. Based on the result, the highest buckling moment value observed when there was no perforation. The diametric view of the section for web perforation $0.3 D$ and $0.75 D$ are shown in Figure 9 (a) and 9(b).

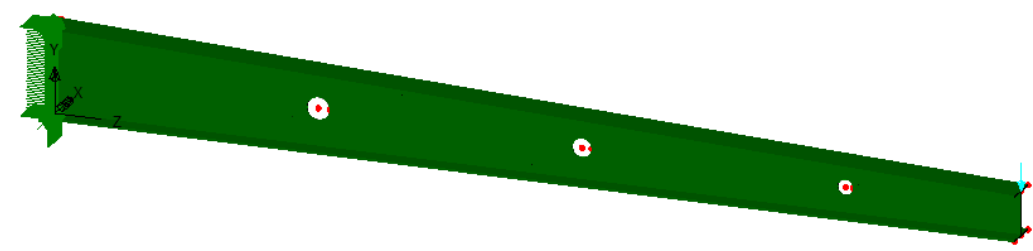

Figure 9(a). Tapered steel section with $0.3 D$ web perforation

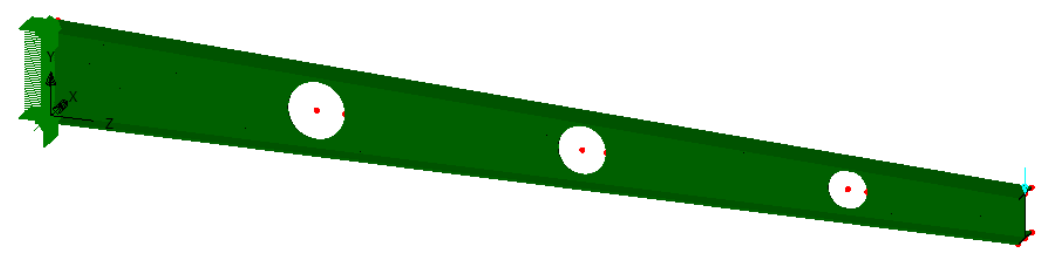

Figure 9(b). Tapered steel section with $0.75 D$ web perforation

When evaluating the effect of the perforation size, each model properties are kept constant. The properties involved are shown in Table 4.

Table 4. Properties of the model

\begin{tabular}{cc}
\hline Length, $L$ & $5500 \mathrm{~mm}$ \\
Depth, $D$ & $500 \mathrm{~mm}$ \\
Width, $B$ & $200 \mathrm{~mm}$ \\
Thickness of Flange, $t_{\mathrm{f}}$ & $13 \mathrm{~mm}$ \\
Thickness of Web, $t_{\mathrm{w}}$ & $9 \mathrm{~mm}$ \\
Concentrated Load, $P$ & $10 \mathrm{kN}$ \\
Distance of $1^{\text {st }}$ perforation to fixed end & $1500 \mathrm{~mm}$ \\
Distance of $2^{\text {nd }}$ perforation to fixed end & $3000 \mathrm{~mm}$ \\
Distance of $3^{\text {rd }}$ perforation to fixed end & $4500 \mathrm{~mm}$ \\
Shape of Perforation & Circle \\
Tapering Ratio & 0.5 \\
Perforation Layout & Open-Open-Open \\
\hline
\end{tabular}




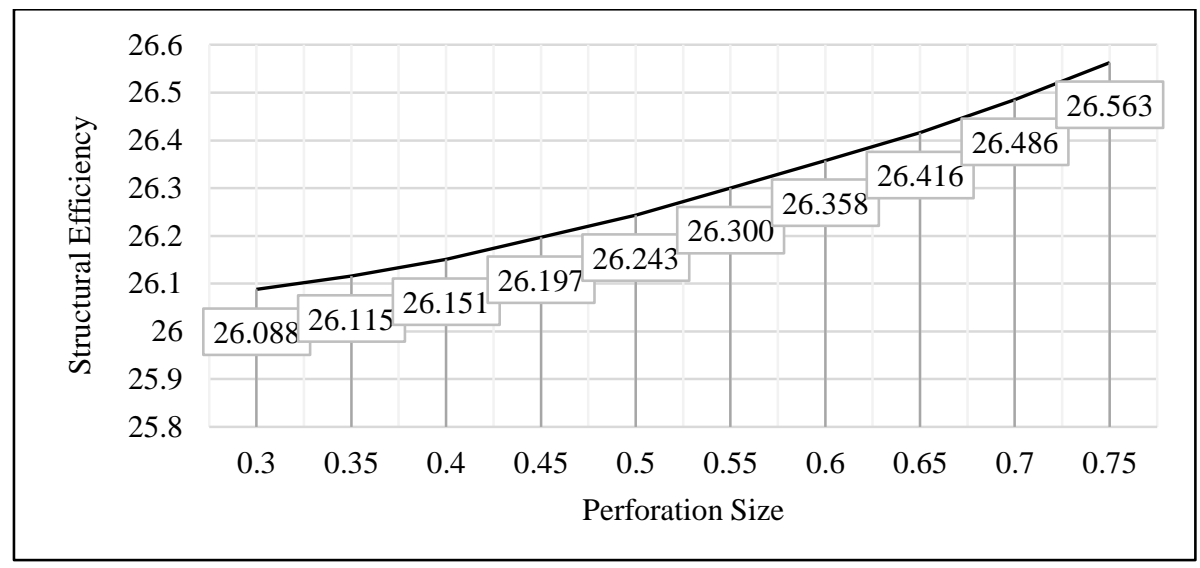

Figure 10. Graph of Structural Efficiency against Perforation Size

However, according to Figure 10, the efficiency increases when the size of the perforation increases. This was due to the percentage reduction (Table 5) in buckling moment was smaller than the percentage reduction of the self-weight of the tapered beam. Therefore, it can be concluded that the tapered steel section with $0.75 \mathrm{D}$ circular perforation was the most efficient section.

Table 5. Buckling moment, $M_{\mathrm{b}}$ and structural efficiency for $5.5 \mathrm{~m}$ span and ratio of tapering of 0.5 with circular perforation size varies from $0.3 \mathrm{D}$ to $0.75 \mathrm{D}$

\begin{tabular}{ccccccc}
\hline $\begin{array}{c}\text { Perforation } \\
\text { Size }\end{array}$ & Eigenvalue & $\begin{array}{c}M_{\mathrm{b}} \\
(\mathrm{kNm})\end{array}$ & $\begin{array}{c}\text { Percentage } \\
\text { Reduction } \\
(\%)\end{array}$ & $\begin{array}{c}\text { Self- } \\
\text { weight } \\
(\mathrm{kN})\end{array}$ & $\begin{array}{c}\text { Structural } \\
\text { Efficiency }\end{array}$ & $\begin{array}{c}\text { Percentage } \\
\text { Increase }(\%)\end{array}$ \\
\hline 0 & 6.854 & 94.243 & - & 3.632 & 25.948 & - \\
$0.3 D$ & 6.853 & 94.229 & 0.015 & 3.612 & 26.088 & 0.539 \\
$0.35 D$ & 6.847 & 94.146 & 0.102 & 3.605 & 26.115 & 0.646 \\
$0.4 D$ & 6.841 & 94.064 & 0.190 & 3.597 & 26.151 & 0.782 \\
$0.45 D$ & 6.834 & 93.968 & 0.292 & 3.587 & 26.197 & 0.959 \\
$0.5 D$ & 6.827 & 93.871 & 0.394 & 3.577 & 26.243 & 1.138 \\
$0.55 D$ & 6.819 & 93.761 & 0.511 & 3.565 & 26.300 & 1.359 \\
$0.6 D$ & 6.809 & 93.624 & 0.657 & 3.552 & 26.358 & 1.581 \\
$0.65 D$ & 6.799 & 93.486 & 0.802 & 3.539 & 26.416 & 1.804 \\
$0.7 D$ & 6.788 & 93.335 & 0.963 & 3.524 & 26.486 & 2.072 \\
$0.75 D$ & 6.777 & 93.184 & 1.123 & 3.508 & 26.563 & 2.372 \\
\hline
\end{tabular}

Beam with web perforation must be located at the centreline (Lagoros et. al, 2008). The maximum diameter of the perforation used not exceeds $0.75 \mathrm{D}$ because an extremely large perforation cause the shear and moment capacities reduced. Based on this analysis, when the perforation sizes equal to $0.75 D$, lower buckling moment value $(93.184 \mathrm{kNm})$ observed compared to that of $0.3 \mathrm{D}$ where the buckling moment value is $94.243 \mathrm{kNm}$. Meanwhile, the distance that used between adjacent perforations is $1500 \mathrm{~mm}$ which is more than the total height of the beam which is $500 \mathrm{~mm}$ where the distance between the edges of adjacent perforation should not be less than the total height of the beam. Therefore, it could avoid web buckling phenomena.

Besides that, $h_{\min } / h_{\max }$ also contributes some effect to the lateral torsional buckling behaviour. For this analysis, $h_{\max }$ were fixed to $500 \mathrm{~mm}$ but $h_{\min }$ based on perforation which are $0.3 D, 0.35 D, 0.4 D, 0.45 D, 0.5 D$, $0.55 D, 0.6 D, 0.65 D, 0.7 D$ and $0.75 D . h_{\max }$ is equal to the section depth, $D$. When the perforation size equal to $0.3 D, h_{\min }$ is $150 \mathrm{~mm}$ and the perforation size equal to $0.75 D, h_{\min }$ is $375 \mathrm{~mm}$. As shown in Table 5 , buckling moment capacity, $M_{\mathrm{b}}$ reduces when the ratio of $h_{\min } / h_{\max }$ changed from 0.3 to 1.3 . But in term of structural efficiency, it was increases from 26.088 to 26.563 . The ratio of $h_{\min } / h_{\max }$ equal to 1.3 was suggested because it 
was able to withstand the failure more than $h_{\min } / h_{\max }$ equal to 0.3 . The section self-weight are proportional to the buckling moment value.

\subsection{Effect of Perforation Shape}

Three different perforation shapes namely circle, square and diamond were modelled using LUSAS software with perforation size of $0.3 D, 0.35 D, 0.4 D, 0.45 D, 0.5 D, 0.55 D, 0.6 D, 0.65 D, 0.7 D$ and $0.75 D$. The diametric view of the three different perforation shapes with $0.5 D$ perforation size was as shown in Figure 11(a), 11(b) and 11(c). Figure 11(c) shows that the diamond shape have the lowest structural efficiency while the square shape has the highest structural efficiency. This is due to the largest reduction in the self-weight compared to the circular and square perforation.

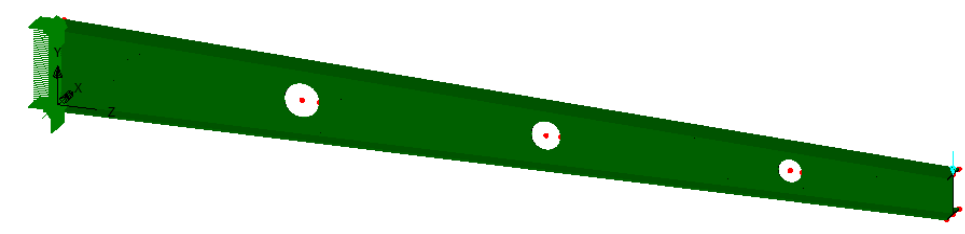

Figure 11(a). Circular Perforation Shape

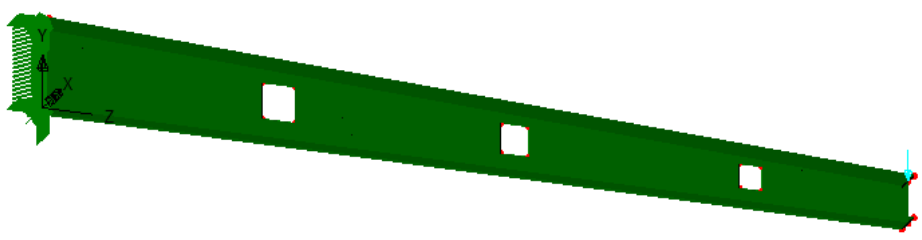

Figure 11(b). Square Perforation Shape

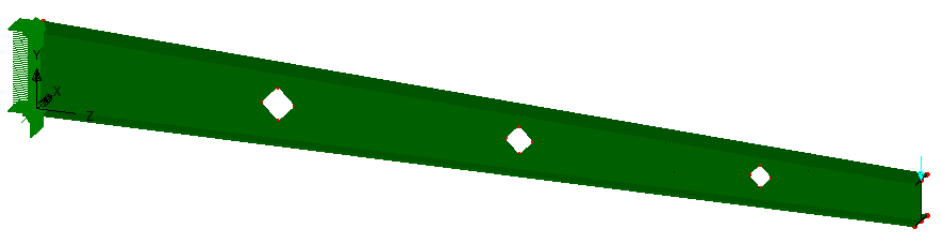

Figure 11(c). Diamond Perforation Shape

For this part, all other properties of the model were kept constant when evaluating the effect of the perforation shape. The properties of the model that were kept constant are shown in Table 6 .

Table 6. Properties of the model

\begin{tabular}{cc} 
Length, $L$ & $5500 \mathrm{~mm}$ \\
Depth, $D$ & $500 \mathrm{~mm}$ \\
Width, $B$ & $200 \mathrm{~mm}$ \\
Thickness of Flange, $\mathrm{t}_{\mathrm{f}}$ & $13 \mathrm{~mm}$ \\
Thickness of Web, $t_{\mathrm{w}}$ & $9 \mathrm{~mm}$ \\
Concentrated Load, $P$ & $10 \mathrm{kN}$ \\
Distance of $1^{\text {st }}$ perforation to fixed end & $1500 \mathrm{~mm}$ \\
Distance of $2^{\text {nd }}$ perforation to fixed end & $3000 \mathrm{~mm}$ \\
Distance of $3^{\text {rd }}$ perforation to fixed end & $4500 \mathrm{~mm}$ \\
Size of Perforation & $0.5 D$ \\
Tapering Ratio & 0.5 \\
Perforation Layout & Open-Open-Open \\
\hline
\end{tabular}


From the results shown in Tables 7 and 8, the buckling moment that resisted by a tapered beam with the circular perforation is higher than tapered beam with square perforation with a circular perforation of $0.75 \mathrm{D}$ shows the value of $6.777 \mathrm{kNm}$ while the square perforation of $0.75 \mathrm{D}$ shows the value of $6.757 \mathrm{kNm}$. Therefore, this was agreeable with the findings from Rodrigues et. al, 2014 where beam with circular perforation presented an ultimate load five times higher than beams with rectangular perforation and two and a half times higher than beams with square perforation. However, the tapered beam with diamond perforation could resist the largest buckling moment among the three different shapes. On the other hand, graphs in Figure 12 show that the diamond has the lowest structural efficiency while the square has the highest structural efficiency. This was due to the highest reduction in the self-weight for $0.75 \mathrm{D}$ perforation size compared to the circular and square perforation where the self-weight for square perforation was $3.474 \mathrm{kN}$, meanwhile for the diamond perforation was $3.553 \mathrm{kN}$. It was about $2.27 \%$ differences between the self-weight of diamond and square perforation. The results also show that the percentage difference of structural efficiency increases when the perforation size increases and for square perforation size of $0.75 D$ the percentage increase was $3.07 \%$ which was higher than circular perforation size of $0.75 \mathrm{D}$ which is $2.37 \%$ and diamond perforation size of $0.75 \mathrm{D}$ which was $1.40 \%$. Hasan et. al, (2017) state that square has the lowest self-weight in her research. It was also reported that diamond perforation shape could resist the highest buckling load which was the same with the findings in this research. It was also found that a square perforation shape has the lowest self-weight among the three shapes of perforation.

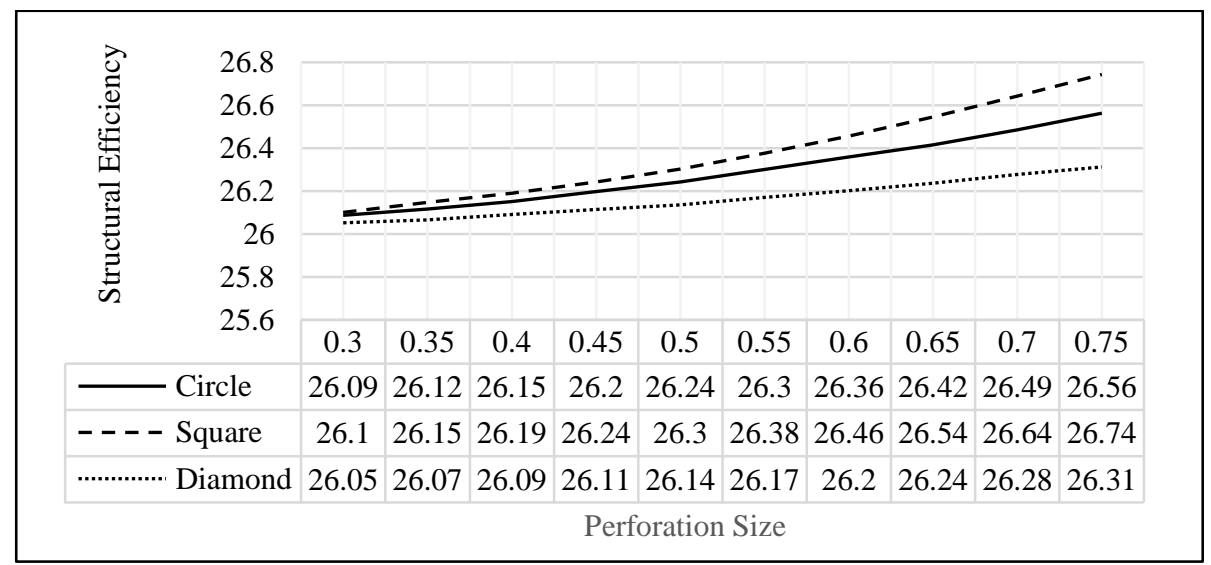

Figure 12. Graph of Structural Efficiency against Perforation Size

Table 7. Buckling moment, $M_{\mathrm{b}}$ and structural efficiency for $5.5 \mathrm{~m}$ span and ratio of tapering of 0.5 with square perforation size varies from $0.3 D$ to $0.75 D$

\begin{tabular}{ccccccc}
\hline $\begin{array}{c}\text { Perforation } \\
\text { Size }\end{array}$ & Eigenvalue & $\begin{array}{c}M_{\mathrm{b}} \\
(\mathrm{kNm})\end{array}$ & $\begin{array}{c}\text { Percentage } \\
\text { Reduction } \\
(\%)\end{array}$ & $\begin{array}{c}\text { Self- } \\
\text { weight } \\
(\mathrm{kN})\end{array}$ & $\begin{array}{c}\text { Structural } \\
\text { Efficiency }\end{array}$ & $\begin{array}{c}\text { Percentage } \\
\text { Increase (\%) }\end{array}$ \\
\hline 0 & 6.854 & 94.243 & - & 3.632 & 25.948 & - \\
$0.3 D$ & 6.847 & 94.146 & 0.102 & 3.607 & 26.101 & 0.590 \\
$0.35 D$ & 6.840 & 94.050 & 0.204 & 3.597 & 26.147 & 0.767 \\
$0.4 D$ & 6.832 & 93.940 & 0.321 & 3.587 & 26.189 & 0.930 \\
$0.45 D$ & 6.823 & 93.816 & 0.452 & 3.575 & 26.242 & 1.135 \\
$0.5 D$ & 6.814 & 93.693 & 0.584 & 3.562 & 26.303 & 1.370 \\
$0.55 D$ & 6.804 & 93.555 & 0.730 & 3.547 & 26.376 & 1.649 \\
$0.6 D$ & 6.794 & 93.418 & 0.875 & 3.531 & 26.456 & 1.960 \\
$0.65 D$ & 6.782 & 93.253 & 1.050 & 3.513 & 26.545 & 2.301 \\
$0.7 D$ & 6.770 & 93.088 & 1.226 & 3.494 & 26.642 & 2.676 \\
$0.75 D$ & 6.757 & 92.909 & 1.415 & 3.474 & 26.744 & 3.069 \\
\hline
\end{tabular}


Table 8. Buckling moment, $M_{\mathrm{b}}$ and structural efficiency for $5.5 \mathrm{~m}$ span and ratio of tapering of 0.5 with diamond perforation size varies from $0.3 D$ to $0.75 D$

\begin{tabular}{ccccccc}
\hline $\begin{array}{c}\text { Perforation } \\
\text { Size }\end{array}$ & Eigenvalue & $\begin{array}{c}M_{\mathrm{b}} \\
(\mathrm{kNm})\end{array}$ & $\begin{array}{c}\text { Percentage } \\
\text { Reduction } \\
(\%)\end{array}$ & $\begin{array}{c}\text { Self- } \\
\text { weight } \\
(\mathrm{kN})\end{array}$ & $\begin{array}{c}\text { Structural } \\
\text { Efficiency }\end{array}$ & $\begin{array}{c}\text { Percentage } \\
\text { Increase (\%) }\end{array}$ \\
\hline 0 & 6.854 & 94.243 & - & 3.632 & 25.948 & - \\
$0.3 D$ & 6.857 & 94.284 & -0.044 & 3.619 & 26.052 & 0.403 \\
$0.35 D$ & 6.853 & 94.229 & 0.015 & 3.615 & 26.066 & 0.456 \\
$0.4 D$ & 6.848 & 94.160 & 0.088 & 3.609 & 26.090 & 0.549 \\
$0.45 D$ & 6.843 & 94.091 & 0.160 & 3.603 & 26.115 & 0.643 \\
$0.5 D$ & 6.837 & 94.009 & 0.248 & 3.597 & 26.135 & 0.723 \\
$0.55 D$ & 6.831 & 93.926 & 0.336 & 3.589 & 26.171 & 0.859 \\
$0.6 D$ & 6.824 & 93.830 & 0.438 & 3.581 & 26.202 & 0.980 \\
$0.65 D$ & 6.816 & 93.720 & 0.554 & 3.572 & 26.237 & 1.116 \\
$0.7 D$ & 6.809 & 93.624 & 0.657 & 3.563 & 26.277 & 1.267 \\
$0.75 D$ & 6.799 & 93.486 & 0.802 & 3.553 & 26.312 & 1.403 \\
\hline
\end{tabular}

\subsection{Effect of Perforation Layout}

Three different perforation layouts for each perforation size were analysed using LUSAS software. The three different perforation layouts are Open-Open-Open (OOO), Open-Close-Open (OCO) and Close-Open-Close (COC) as found in Figure 13(a), 13(b) to 13(c). From the graph shown in Figure 14, Open-Open-Open (OOO) layout shows the highest structural efficiency. Although Close-Open-Close (COC) layout could resist the largest buckling moment due to higher self-weight thus reducing its structural efficiency. Therefore, Open-Open-Open (OOO) layout was the most structurally efficient layout.

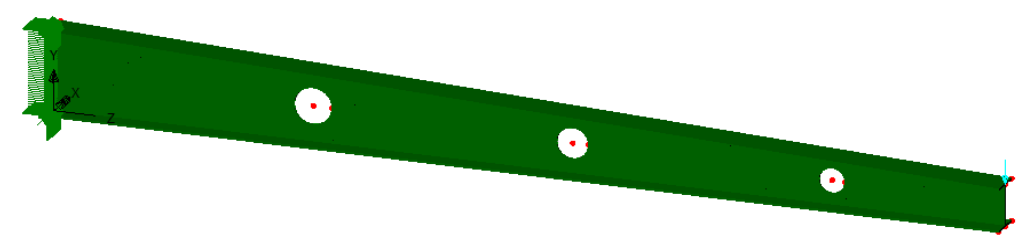

Figure 13(a). Open-Open-Open (OOO) Layout

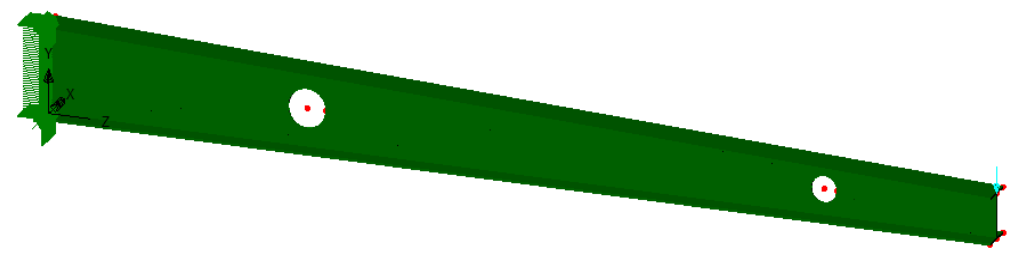

Figure 13(b). Open-Close-Open (OCO) Layout

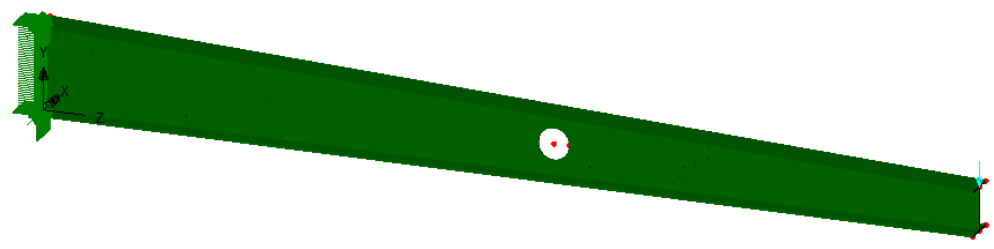

Figure 13(c) Close-Open-Close (COC) Layout 
When evaluating the effect of different perforation layout, all other properties of the model were kept constant. The properties of the model that were kept constant are shown in Table 9.

Table 9. Properties of the model

\begin{tabular}{cc}
\hline Length, $L$ & $5500 \mathrm{~mm}$ \\
Depth, $D$ & $500 \mathrm{~mm}$ \\
Width, $B$ & $200 \mathrm{~mm}$ \\
Thickness of Flange, $t_{\mathrm{f}}$ & $13 \mathrm{~mm}$ \\
Thickness of Web, $t_{\mathrm{w}}$ & $9 \mathrm{~mm}$ \\
Concentrated Load, $P$ & $10 \mathrm{kN}$ \\
Distance of $1^{\text {st }}$ perforation to fixed end & $1500 \mathrm{~mm}$ \\
Distance of $2^{\text {nd }}$ perforation to fixed end & $3000 \mathrm{~mm}$ \\
Distance of $3^{\text {rd }}$ perforation to fixed end & $4500 \mathrm{~mm}$ \\
Size of Perforation & $0.5 D$ \\
Shape of Perforation & Circle \\
Tapering Ratio & 0.5 \\
\hline
\end{tabular}

From Table 10, it is shown that the buckling moment was the highest for the Close-Open-Close (COC) layout. This was due to it has the least number of perforation among the three different layouts. COC layout has only one perforation compared to two perforations in OCO layout and three perforations in OOO layout. Open-Open-Open (OOO) layout could withstand the lowest buckling moment due to more number of perforation. However, from the graph shown in Figure 14, Open-Open-Open (OOO) layout shows the highest structural efficiency. This was due to the percentage of reduction in self-weight was higher than the percentage increase in the buckling moment. Therefore, although Close-Open-Close (COC) layout could resist the largest buckling moment it has a larger self-weight thus reducing its structural efficiency. The results also show that the percentage increase in structural efficiency is higher when the perforation size increases and the highest percentage increase for a circular perforation shape of $0.75 \mathrm{D}$ with the OOO perforation layout which was $2.37 \%$. Therefore, Open-Open-Open (OOO) layout was the most structurally efficient layout.

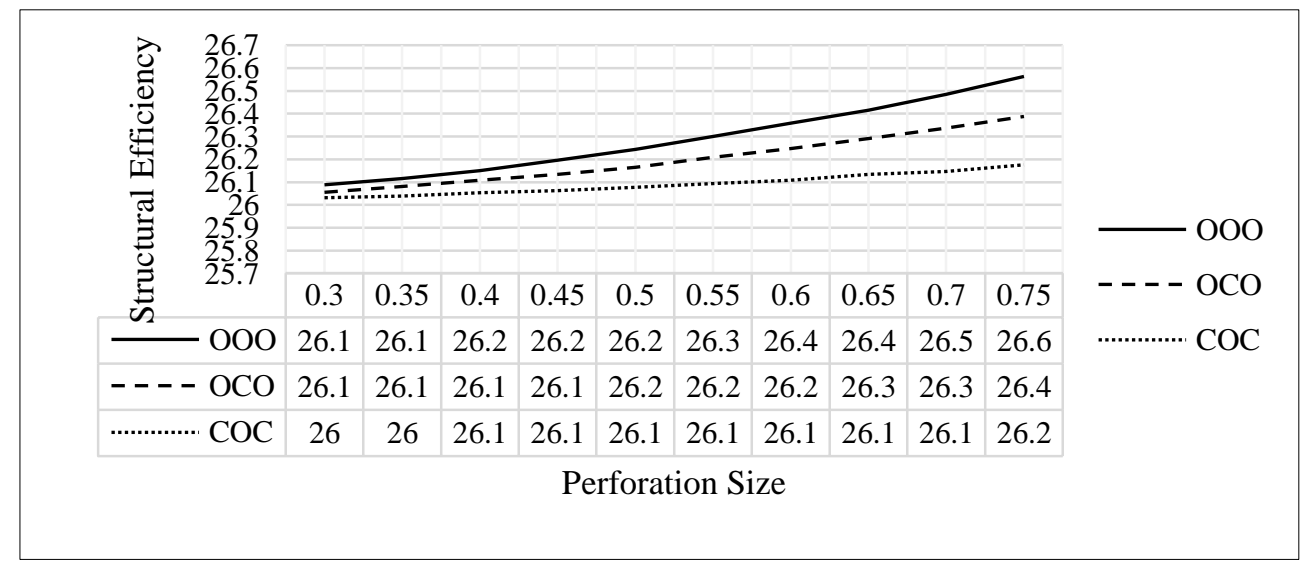

Figure 14. Graph of Structural Efficiency against Perforation Size 
Table 10. Buckling moment, $M_{\mathrm{b}}$ and structural efficiency for $5.5 \mathrm{~m}$ span and ratio of tapering of 0.5 with circle perforation size varies from $0.3 D$ to $0.75 D$ with different perforation layout

\begin{tabular}{|c|c|c|c|c|c|c|c|}
\hline $\begin{array}{l}\text { Perforation } \\
\quad \text { Size }\end{array}$ & $\begin{array}{c}\text { Perforation } \\
\text { Layout }\end{array}$ & $\begin{array}{l}\text { Eigenv } \\
\text { alue }\end{array}$ & $\begin{array}{c}M_{\mathrm{b}} \\
(\mathrm{kNm})\end{array}$ & $\begin{array}{c}\text { Percentage } \\
\text { Reduction } \\
(\%)\end{array}$ & $\begin{array}{c}\text { Self- } \\
\text { weight } \\
(\mathrm{kN})\end{array}$ & $\begin{array}{l}\text { Structural } \\
\text { Efficiency }\end{array}$ & $\begin{array}{l}\text { Percentage } \\
\text { Increase }(\%)\end{array}$ \\
\hline 0 & - & 6.854 & 94.243 & - & 3.632 & 25.948 & - \\
\hline $0.3 D$ & $\mathrm{OOO}$ & 6.853 & 94.229 & 0.015 & 3.612 & 26.088 & 0.539 \\
\hline $0.3 D$ & $\mathrm{OCO}$ & 6.858 & 94.298 & -0.058 & 3.619 & 26.056 & 0.418 \\
\hline $0.3 D$ & $\mathrm{COC}$ & 6.863 & 94.366 & -0.131 & 3.625 & 26.032 & 0.325 \\
\hline $0.35 D$ & $\mathrm{OOO}$ & 6.847 & 94.146 & 0.102 & 3.605 & 26.115 & 0.646 \\
\hline $0.35 D$ & OCO & 6.855 & 94.256 & -0.015 & 3.614 & 26.081 & 0.513 \\
\hline $0.35 D$ & $\mathrm{COC}$ & 6.861 & 94.339 & -0.102 & 3.623 & 26.039 & 0.351 \\
\hline $0.4 D$ & $\mathrm{OOO}$ & 6.841 & 94.064 & 0.190 & 3.597 & 26.151 & 0.782 \\
\hline $0.4 D$ & $\mathrm{OCO}$ & 6.851 & 94.201 & 0.044 & 3.608 & 26.109 & 0.621 \\
\hline $0.4 D$ & $\mathrm{COC}$ & 6.859 & 94.311 & -0.073 & 3.620 & 26.053 & 0.405 \\
\hline $0.45 D$ & $\mathrm{OOO}$ & 6.834 & 93.968 & 0.292 & 3.587 & 26.197 & 0.959 \\
\hline $0.45 D$ & OCO & 6.846 & 94.133 & 0.117 & 3.602 & 26.133 & 0.715 \\
\hline $0.45 D$ & $\mathrm{COC}$ & 6.856 & 94.270 & -0.029 & 3.617 & 26.063 & 0.444 \\
\hline $0.5 D$ & $\mathrm{OOO}$ & 6.827 & 93.871 & 0.394 & 3.577 & 26.243 & 1.138 \\
\hline $0.5 D$ & OCO & 6.841 & 94.064 & 0.190 & 3.595 & 26.165 & 0.838 \\
\hline $0.5 D$ & $\mathrm{COC}$ & 6.854 & 94.243 & 0 & 3.614 & 26.077 & 0.498 \\
\hline $0.55 D$ & $\mathrm{OOO}$ & 6.819 & 93.761 & 0.511 & 3.565 & 26.300 & 1.359 \\
\hline $0.55 D$ & $\mathrm{OCO}$ & 6.837 & 94.009 & 0.248 & 3.587 & 26.208 & 1.003 \\
\hline $0.55 D$ & $\mathrm{COC}$ & 6.851 & 94.201 & 0.044 & 3.610 & 26.095 & 0.565 \\
\hline $0.6 D$ & $\mathrm{OOO}$ & 6.809 & 93.624 & 0.657 & 3.552 & 26.358 & 1.581 \\
\hline $0.6 D$ & $\mathrm{OCO}$ & 6.830 & 93.913 & 0.350 & 3.578 & 26.247 & 1.154 \\
\hline $0.6 D$ & $\mathrm{COC}$ & 6.847 & 94.146 & 0.102 & 3.606 & 26.108 & 0.618 \\
\hline $0.65 D$ & $\mathrm{OOO}$ & 6.799 & 93.486 & 0.802 & 3.539 & 26.416 & 1.804 \\
\hline $0.65 D$ & OCO & 6.824 & 93.830 & 0.438 & 3.569 & 26.290 & 1.320 \\
\hline $0.65 D$ & $\mathrm{COC}$ & 6.844 & 94.105 & 0.146 & 3.601 & 26.133 & 0.714 \\
\hline $0.7 D$ & $\mathrm{OOO}$ & 6.788 & 93.335 & 0.963 & 3.524 & 26.486 & 2.072 \\
\hline $0.7 D$ & OCO & 6.817 & 93.734 & 0.540 & 3.559 & 26.337 & 1.500 \\
\hline $0.7 D$ & $\mathrm{COC}$ & 6.840 & 94.05 & 0.204 & 3.597 & 26.147 & 0.767 \\
\hline $0.75 D$ & $\mathrm{OOO}$ & 6.777 & 93.184 & 1.123 & 3.508 & 26.563 & 2.372 \\
\hline $0.75 D$ & OCO & 6.809 & 93.624 & 0.657 & 3.548 & 26.388 & 1.695 \\
\hline $0.75 D$ & $\mathrm{COC}$ & 6.836 & 93.995 & 0.263 & 3.591 & 26.175 & 0.876 \\
\hline
\end{tabular}

\subsection{Effect of Tapering Ratio}

A total of 10 different tapering ratios for tapered steel section with perforation were analysed using LUSAS software. The tapering ratios involved are $0.3,0.35,0.4,0.45,0.5,0.55,0.6,0.65,0.7$ and 0.75 . The diametric view the tapered steel section with a tapering ratio of 0.3 and 0.75 are shown in Figure 15(a) and 15(b). When evaluating the effect of tapering ratio of the tapered steel section, the properties of the model that were kept constant are shown in Table 11. The buckling moment was the highest when the tapering ratio was 
0.3 and it also has the lowest self-weight. Therefore, according to Figure 16, the tapering ratio of 0.3 has the highest structural efficiency and this was due to its low self-weight and could withstand a higher buckling moment before failure.

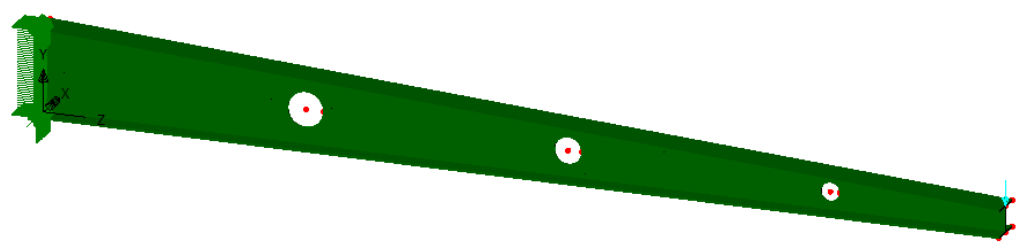

Figure 15(a). Tapered steel section with 0.3 tapering ratio

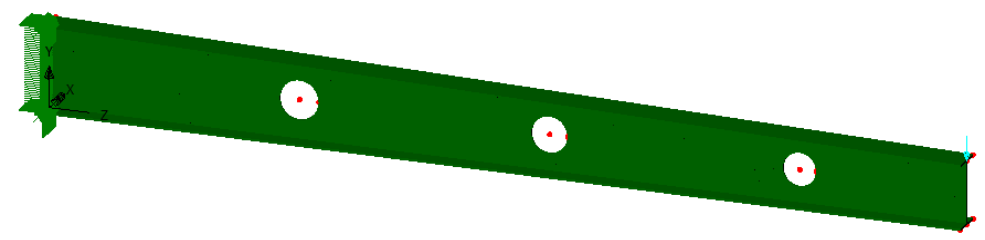

Figure 15(b). Tapered steel section with 0.75 tapering ratio

Table 11. Properties of the model

\begin{tabular}{cc}
\hline Length, $L$ & $5500 \mathrm{~mm}$ \\
Depth, $D$ & $500 \mathrm{~mm}$ \\
Width, $B$ & $200 \mathrm{~mm}$ \\
Thickness of Flange, $t_{\mathrm{f}}$ & $13 \mathrm{~mm}$ \\
Thickness of Web, $t_{\mathrm{w}}$ & $9 \mathrm{~mm}$ \\
Concentrated Load, $P$ & $10 \mathrm{kN}$ \\
Distance of $1^{\text {st }}$ perforation to fixed end & $1500 \mathrm{~mm}$ \\
Distance of $2^{\text {nd }}$ perforation to fixed end & $3000 \mathrm{~mm}$ \\
Distance of $3^{\text {rd }}$ perforation to fixed end & $4500 \mathrm{~mm}$ \\
Size of Perforation & $0.5 D$ \\
Shape of Perforation & Circle \\
Perforation Layout & Open-Open-Open \\
\hline
\end{tabular}

The lateral buckling load of a tapered beam with equal flange with tapering ratio of 0.5 was higher than tapered beam with a tapering ratio of 1.0 (Asgarian et. al, 2013). When the tapering ratio increases, the buckling moment decreases (Benyamina et. al, 2013). According to results in Table 12, the buckling moment decreases when the tapering ratio increases which was in line with the findings above. The buckling moment was the highest when the tapering ratio was 0.3 and it also has the lowest self-weight. Therefore, a tapering ratio of 0.3 has the highest structural efficiency and this was due to its low self-weight and could withstand a higher buckling moment before failure. It also has the highest percentage increase in structural efficiency which was at $114.36 \%$. The tapering ratio of 1.0 was used as a control model to determine the percentage increase in the structural efficiency of all the models and therefore it was not included in the graph. 
Table 12. Buckling moment, $M_{\mathrm{b}}$ and structural efficiency for $5.5 \mathrm{~m}$ span with $0.5 \mathrm{D}$ circular perforation size with Open-Open-Open $(\mathrm{OOO})$ perforation layout and tapering ratio varies from 0.3 to 0.75

\begin{tabular}{cccccc}
\hline $\begin{array}{c}\text { Tapering } \\
\text { Ratio }\end{array}$ & Eigenvalue & $M_{\mathrm{b}}(\mathrm{kNm})$ & $\begin{array}{c}\text { Self-weight } \\
(\mathrm{kN})\end{array}$ & $\begin{array}{c}\text { Structural } \\
\text { Efficiency }\end{array}$ & $\begin{array}{c}\text { Percentage Increase } \\
(\%)\end{array}$ \\
\hline 0.3 & 9.302 & 127.903 & 3.396 & 37.663 & 114.36 \\
0.35 & 8.497 & 116.834 & 3.442 & 33.944 & 93.19 \\
0.40 & 7.827 & 107.621 & 3.488 & 30.855 & 75.61 \\
0.45 & 7.276 & 100.045 & 3.535 & 28.301 & 61.08 \\
0.50 & 6.827 & 93.871 & 3.573 & 26.272 & 49.53 \\
0.55 & 6.459 & 88.811 & 3.619 & 24.540 & 39.67 \\
0.60 & 6.160 & 84.700 & 3.666 & 23.104 & 31.50 \\
0.65 & 5.915 & 81.331 & 3.704 & 21.958 & 24.97 \\
0.70 & 5.716 & 78.595 & 3.75 & 20.959 & 19.29 \\
0.75 & 5.554 & 76.368 & 3.797 & 20.113 & 14.47 \\
1.0 & 5.119 & 51.19 & 4.006 & 17.570 & - \\
\hline
\end{tabular}

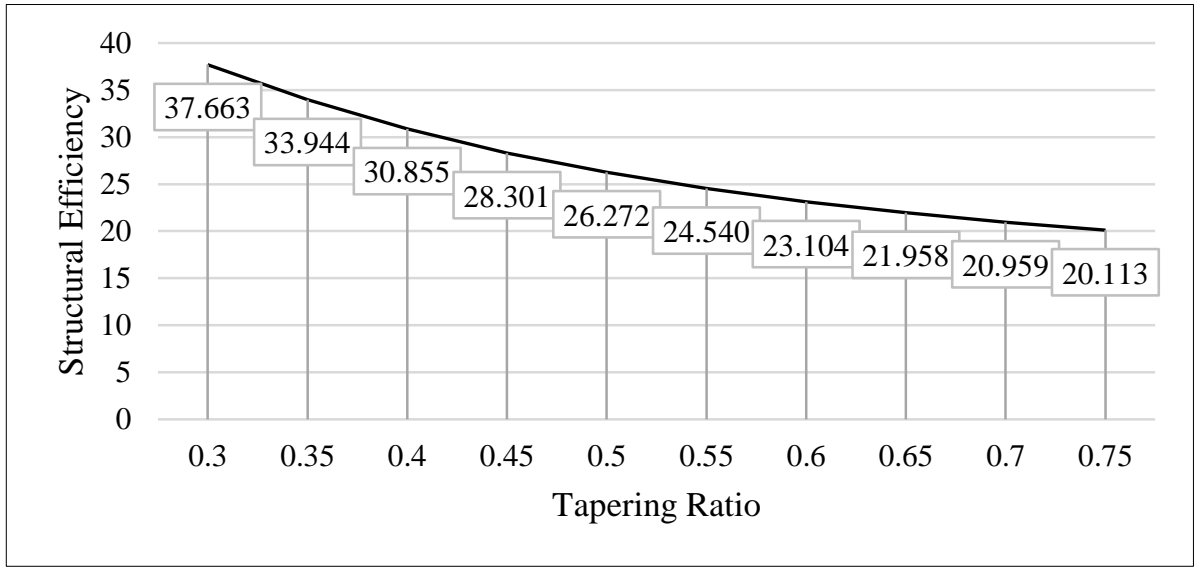

Figure 16. Graph of Structural Efficiency against Tapering Ratio

As found in Yuan et. al, 2013, for steel cantilevers web with narrow flange (width/depth $=0.19$ ), tapering reduces the buckling load up to $10 \%$ and $6 \%$ for the tip point loading and the uniformly distributed load respectively. On the other hand, for a beam with a relatively wide flange (width/depth $=0.96$ ), tapering increases the buckling load by $2 \%$. Generally, as the beam length increases, the difference in the buckling loads gradually increases for the cases of uniformly distributed load.

However, for the buckling moments, the tapering web section contributes to the lowest effects (Kus, 2015). About $11 \%$ difference in values between critical buckling moments for web tapered beam and the prismatic beam was observed. Therefore, due to load resistance to the lateral-torsional bucking, flange and web of the tapered sections was truly advantageous since representing the lighter section compared to other section.

\subsection{Effect of Flange Thickness}

A total of 11 sizes of flange thicknesses was analysed using LUSAS software to evaluate effect on lateral-torsional buckling behaviour. The flange thickness involved are $0.01 \mathrm{~m}, 0.011 \mathrm{~m}, 0.012 \mathrm{~m}, 0.013 \mathrm{~m}$, $0.014 \mathrm{~m}, 0.015 \mathrm{~m}, 0.016 \mathrm{~m}, 0.017 \mathrm{~m}, 0.018 \mathrm{~m}, 0.019 \mathrm{~m}$ and $0.020 \mathrm{~m}$. Each model porperties were kept constant to observe the effect of the flange thickness of tapered steel section. The properties of the model that were kept constant are shown in Table 13. According to the result, the buckling moment increases when the flange thickness increases as it has higher bending strength. When the flange thickness increases, it would cause the self-weight to increase as well. However, the increase in the buckling moment resistance was higher than the 
increase in the self-weight. Therefore, structural efficiency increases when the flange thickness increases according to Figure 17. Flange thickness of $0.020 \mathrm{~m}$ has the highest structural efficiency.

Table 13. Properties of the model

\begin{tabular}{cc} 
Length, $L$ & $5500 \mathrm{~mm}$ \\
Depth, $D$ & $500 \mathrm{~mm}$ \\
Width, $B$ & $200 \mathrm{~mm}$ \\
Thickness of Web, $t_{\mathrm{w}}$ & $9 \mathrm{~mm}$ \\
Concentrated Load, $P$ & $10 \mathrm{kN}$ \\
Distance of $1^{\text {st }}$ perforation to fixed end & $1500 \mathrm{~mm}$ \\
Distance of $2^{\text {nd }}$ perforation to fixed end & $3000 \mathrm{~mm}$ \\
Distance of $3^{\text {rd }}$ perforation to fixed end & $4500 \mathrm{~mm}$ \\
Shape of Perforation & Circle \\
Tapering Ratio & 0.5 \\
Perforation Layout & Open-Open-Open \\
\hline
\end{tabular}

When the flange thickness increases, the buckling moment increases as well under the same span length (Hasan et. al, 2017). The twist in lateral-torsional buckling was resisted by the section's torsional stiffness which was mainly governed by the flange thickness of the beam (Sehwail, 2013). Therefore, the beam with the thicker flange will have more bending strength. According to the results in Table 14, the buckling moment increases when the flange thickness increases as it has higher bending strength. This was the same with the findings from Hasan et. al, 2017 and Sehwail, 2013. When the flange thickness increases, it would cause the self-weight to increase as well. However, the increase in the buckling moment resistance was higher than the increase in the self-weight. Therefore, structural efficiency increases when the flange thickness increases. Flange thickness of $0.020 \mathrm{~m}$ has the highest structural efficiency.

Table 14. Buckling moment, $M_{\mathrm{b}}$ and structural efficiency for $5.5 \mathrm{~m}$ span with $0.5 D$ circular perforation size with Open-Open-Open (OOO) opening layout and flange thickness varies from $0.01 \mathrm{~m}$ to $0.02 \mathrm{~m}$

\begin{tabular}{ccccc}
\hline $\begin{array}{c}\text { Flange thickness } \\
(\mathrm{m})\end{array}$ & Eigenvalue & $\begin{array}{c}M_{\mathrm{b}} \\
(\mathrm{kNm})\end{array}$ & $\begin{array}{c}\text { Self-weight } \\
(\mathrm{kN})\end{array}$ & Structural Efficiency \\
\hline 0.01 & 4.240 & 58.300 & 3.068 & 19.003 \\
0.011 & 5.007 & 68.846 & 3.238 & 21.262 \\
0.012 & 5.870 & 80.713 & 3.407 & 23.690 \\
0.013 & 6.827 & 93.871 & 3.577 & 26.243 \\
0.014 & 7.874 & 108.268 & 3.746 & 28.902 \\
0.015 & 9.008 & 123.860 & 3.915 & 31.637 \\
0.016 & 10.230 & 140.663 & 4.085 & 34.434 \\
0.017 & 11.520 & 158.400 & 4.254 & 37.236 \\
0.018 & 12.890 & 177.238 & 4.424 & 40.063 \\
0.019 & 14.340 & 197.175 & 4.593 & 42.929 \\
0.020 & 15.850 & 217.938 & 4.763 & 45.756 \\
\hline
\end{tabular}




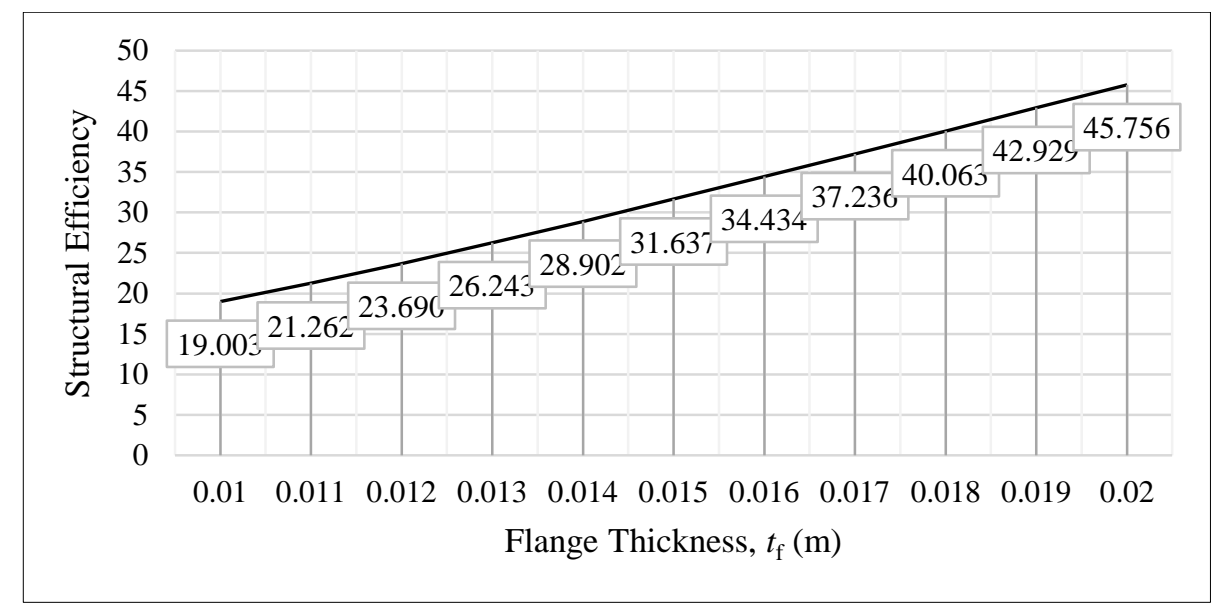

Figure 17. Graph of Structural Efficiency against Flange Thickness

\subsection{Effect of Web Thickness}

A total of 10 sizes of web thickness was analysed using LUSAS software to evaluate its effect on lateraltorsional buckling behaviour. The web thickness involved are $0.006 \mathrm{~m}, 0.007 \mathrm{~m}, 0.008 \mathrm{~m}, 0.009 \mathrm{~m}, 0.010 \mathrm{~m}$, $0.011 \mathrm{~m}, 0.012 \mathrm{~m}, 0.013 \mathrm{~m}, 0.014 \mathrm{~m}$ and $0.015 \mathrm{~m}$. The model properties that are kept constant are shown in Table 15 when evaluating the effect of web thickness. From the results, the buckling moment increases when the web thickness increases. The self-weight of the tapered steel section also increases when the web thickness increases as it involves a thicker web. The structural efficiency increases as well when the web thickness increases. However, the rate of increase in structural efficiency of web thickness was not as high as the rate of increase in structural efficiency of flange thickness. According to Figure 18, web thickness of $0.015 \mathrm{~m}$ has the highest structural efficiency.

Table 15. Properties of the model

\begin{tabular}{cc} 
Length, $L$ & $5500 \mathrm{~mm}$ \\
Depth, $D$ & $500 \mathrm{~mm}$ \\
Width, $B$ & $200 \mathrm{~mm}$ \\
Thickness of Flange, $t_{\mathrm{f}}$ & $13 \mathrm{~mm}$ \\
Concentrated Load, $P$ & $10 \mathrm{kN}$ \\
Distance of $1^{\text {st }}$ perforation to fixed end & $1500 \mathrm{~mm}$ \\
Distance of $2^{\text {nd }}$ perforation to fixed end & $3000 \mathrm{~mm}$ \\
Distance of $3^{\text {rd }}$ perforation to fixed end & $4500 \mathrm{~mm}$ \\
Shape of Perforation & Circle \\
Tapering Ratio & 0.5 \\
Perforation Layout & Open-Open-Open \\
\hline
\end{tabular}

From Table 16, the buckling moment increases when the web thickness increases. The buckling moment of tapered steel section would increase when the thickness of the web increases (Azar et. al, 2016). Therefore, this was the same as the findings in this analysis. The self-weight of the tapered steel section also increases when the web thickness increases as it involves a thicker web. The structural efficiency increases as well when the web thickness increases. However, the rate of increase in structural efficiency of web thickness was not as high as the rate of increase in structural efficiency of flange thickness. Web thickness of $0.015 \mathrm{~m}$ has the highest structural efficiency. 
Table 16. Buckling moment, $M_{\mathrm{b}}$ and structural efficiency for $5.5 \mathrm{~m}$ span with $0.5 D$ circular perforation size with Open-Open-Open (OOO) opening layout and web thickness varies from $0.006 \mathrm{~m}$ to $0.015 \mathrm{~m}$

\begin{tabular}{ccccc}
\hline $\begin{array}{c}\text { Web thickness } \\
(\mathrm{m})\end{array}$ & Eigenvalue & $\begin{array}{c}M_{\mathrm{b}} \\
(\mathrm{kNm})\end{array}$ & $\begin{array}{c}\text { Self-weight } \\
(\mathrm{kN})\end{array}$ & Structural Efficiency \\
\hline 0.006 & 5.774 & 79.393 & 3.118 & 25.463 \\
0.007 & 6.150 & 84.563 & 3.271 & 25.852 \\
0.008 & 6.490 & 89.238 & 3.424 & 26.062 \\
0.009 & 6.827 & 93.871 & 3.577 & 26.243 \\
0.010 & 7.182 & 98.753 & 3.729 & 26.482 \\
0.011 & 7.568 & 104.06 & 3.882 & 26.806 \\
0.012 & 7.993 & 109.904 & 4.034 & 27.244 \\
0.013 & 8.461 & 116.339 & 4.187 & 27.786 \\
0.014 & 8.973 & 123.379 & 4.340 & 28.428 \\
0.015 & 9.530 & 131.038 & 4.492 & 29.171 \\
\hline
\end{tabular}

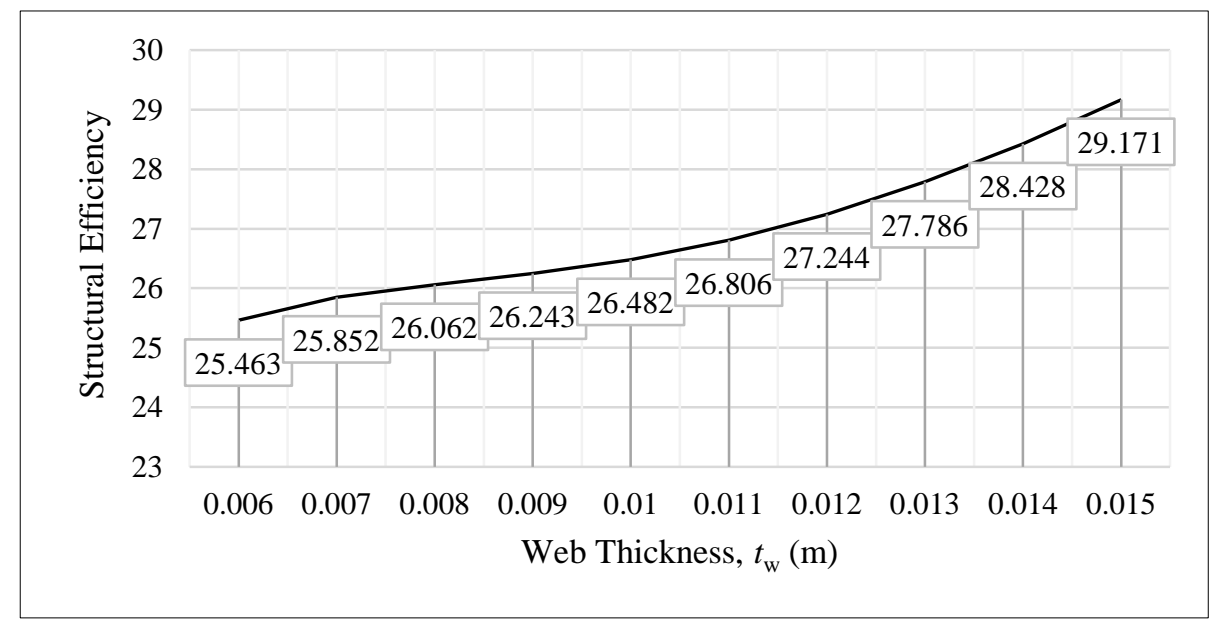

Figure 18. Graph of Structural Efficiency against Web Thickness

\section{Conclusions}

From the results presented in this paper, the conclusions were:

1. The perforation size of $0.75 D$ has the highest structural efficiency. The buckling moment decreases when the perforation size increases thus contribute an increment of structural efficiency.

2. The square perforation shape also has the highest structural efficiency due to its lower self-weight compared to circular and diamond perforation shape.

3. The perforation layout of Open-Open-Open (OOO) shows the highest structural efficiency compared to Open-Close-Open (OCO) layout and Close-Open-Close (COC) layout.

4. The tapering ratio of 0.75 has the highest structural efficiency. The structural efficiency increases when the tapering ratio decreases.

5. Flange thickness of $20 \mathrm{~mm}$ and web thickness of $15 \mathrm{~mm}$ show the highest structural efficiency as these were the thickest section that was used in this analysis. The flange thickness and web thickness increases, the structural efficiency of the tapered steel section with perforation also increases.

6. The displacement was higher for tapered steel section with perforation compared to tapered steel section without perforation. The most efficient tapered steel section with perforation does not show any dissimilarities in term of failure pattern with other tapered steel section with perforation.

7. The most efficient section properties were summarised in Table 17. 
Table 17. Properties of tapered steel section with perforation with the highest structural efficiency

\begin{tabular}{cc}
\hline Parameters & Results \\
\hline Perforation Size & $0.75 D$ \\
Perforation Shape & Square \\
Perforation Layout & Open-Open-Open (OOO) \\
Tapering Ratio & 0.3 \\
Flange Thickness & $20 \mathrm{~mm}$ \\
Web Thickness & $15 \mathrm{~mm}$ \\
\hline
\end{tabular}

Acknowledgments: The authors gratefully recognize the financial support by the Bridging Research Grant 2017 (Account Number: 1001/PAWAM/6316234) provided by the Universiti Sains Malaysia (USM) during the course of this research.

Conflicts of Interest: The authors declare no conflict of interest.

\section{References}

1. Sehwail, M., September 2013. Lateral Torsional Buckling of Steel I-Section Cellular Beams. Master Thesis, Eastern Mediterranean University.

2. American Institute of Steel Construction, 10 January 2018. Ten Reasons to Use Structural Steel. Available online: https://www.aisc.org/why-steel/ten-reasons-to-use-structural-steel/\#.

3. Hasan, H., De'nan, F. and Choong, K. K., 2017. The Efficiency of Structural Steel Section with Perforated-Corrugated Web Profile Subjected to Shear Loading Condition. Engineering Heritage Journal, 2, 5-9

4. Thomas, M.B., 2014. Lateral Torsional Buckling of Flange-Tapered I-Beams. Master Thesis, Brigham Young University

5. Polyzois, D. and Raftoyiannis, I. G., 1998. Lateral-Torsional Stability of Steel Web-Tapered I-Beams. Journal of Structural Engineering, 124, 1208-1216

6. Wijaya, P.K., Swan, C.L.G. and Noor Sadrina, G., 2019. An Analysis of Elastic and Inelastic Lateral Torsional Buckling of Web-Tapered I Beams using the Finite Element Method, MATEC Web of Conferences, 258, 1-6

7. Durif, S., Bochair, A.H. and Vassart, O., 2012. Validation of an Analytical Model for Curved and Tapered Cellular Beams at Normal and Fire Conditions, Civil Engineering, 57, 83-95

8. Rameshbabu, C. and Prabavathy, S., 2018. Simplified Design Equation for Web Tapered I-sections using Finite Element Model. Archives of Civil Engineering, 14, 3, 57-66

9. Asgarian, B., Soltani, M. and Mohri, F., 2013 Lateral-torsional buckling of tapered thin-walled beams with arbitrary cross-sections. Thin-Walled Structures, 62, 96-108

10. Rodrigues, F., Da S. Vellasco, P., De Lima, L. and De Andrade, S., 2014. Finite Element Modelling of Steel Beams with Web Openings. Engineering, 6, 886-913

11. Tankova, T., Martins, J.D., Da Silva, L.S., Somies, R. and Craveiro, D., 2018. Experimental Buckling Behaviour of Web Tapered I-section Steel Columns, Journal of Constructional Steel Research, 147, 293-312

12. Bai, R., Liu, S.-W., Chan, S.-L. and Yu, F., 2019 Flexural Buckling Strength of Tapered-I-Section Steel Columns Based on ANSI/AISC-360-16. International Journal of Structural Stability and Dynamics, $19,11,1-20$

13. Lagoros, N. D., Psarras, L. D., Papadrakakis, M. and Panagiotou, Y., 2008. Optimum Design of Steel Structures with Web Openings. Engineering Structures, 30, 2528-2537

14. Azar, F., Naaim, N., De'nan, F. and Choong, K. K., 2016. Finite Element Analysis of Lateral Tor-sional Buckling Behaviour of Tapered Steel Section with Perforation. MATEC Web of Conferences, 47, 1-6

15. Macdonald, A.J.,2007. Structure \& Architecture, 2nd edn. New York: p. 60-61 
16. Yuan, W-b., Kim, B. and Chen, C-y., 2013. Lateral-Torsional Buckling of Steel Web Tapered Tee-Sections Cantilevers. Journal of Constructional Steel Research, 87, 31-37

17. Kus, J., 2015. Lateral-Torsional Buckling Steel Beams with Simultaneously Tapered Flanges and Web. Steel and Composites Structures, 19, 4, 897-916

18. Kucukler, M., Gardner, L. and Macorini, L., 2015. Lateral-Torsional Buckling Assessment of Steel Beams through a Stiffness Reduction Method, Journal of Constructional Steel Research, 1-33

19. Gunawan, D. and Suryoatmono, B., 2017. Numerical Study on Lateral Torsional Buckling of Honeycomb Beam, Procedia Engineering, 171, 140-146

20. Phuvoravan, K. and Ponsorn, P., 2017. Nonlinear Finite Element Analysis to Evaluate Lateral Torsional Buckling Moment of Elliptical Cellular Steel Beams, Engineering Journal, 21, 93-108

21. Benyamina, A. B., Meftah, S. A., Mohri, F. and Daya, E.M., 2013. Analytical solutions attempt for lateral torsional buckling of doubly symmetric web-tapered I beams. Engineering Structures, 56, 1207-1219.

22. De'nan, F., Hasan, H. and Choong, K. K., 2017. The Efficiency of Structural Steel Section with Perforated-Corrugated Web Profile Subjected to Shear Loading Condition. Engineering Heritage Journal, 1(1), 29-35.

23. Chen, B., Roy, K., Uzzaman, A., Raftery, G. M. and Lim, J. B. P., 2020. Parametric Study and Simplified Design Equations for Cold-formed Steel Channels with Edge-Stiffened Holes under Axial Compression. Journal of Constructional Steel Research, 172, 1-27

24. Chen, B., Roy, K., Uzzaman, A., Raftery, G. M., Nash, D, Clifton, G. C., Pouladi, P. and Lim, J. B. P., 2019. Effects of edge-stiffened web openings on the behaviour of cold-formed steel channel sections under compression. Thin-Walled Structures, 144, 1-21

25. Roy, K., Ting, T. C. H., Lau, H. H. and Lim, J.B.P., 2019. Experimental and Numerical Investigations on the Axial Capacity of Cold-Formed Steel Built-up Box Sections. Journal of Constructional Steel Research, 160, 411-427

26. Roy, K., Ting, T. C. H., Lau, H. H. and Lim, J.B.P., 2019. Effect of thickness on the behaviour of axially loaded back-to-back cold formed steel built-up channel sections - Experimental and numerical investigation. Structures, 16,327-346 